\title{
Judocas olímpicos brasileiros: fatores de apoio psicossocial para o desenvolvimento do talento esportivo
}

CDD. 20.ed. 796.011

796.07

796.81

\author{
Marcelo MASSA* \\ Rudney UEZU $\mathrm{U}^{* * * *+1}$ \\ Maria Tereza Silveira BÖHME**
}

\section{Resumo}

*Escola de Artes, Ciências e Humanidades, Universidade de São Paulo;

**Escola de Educação Física e Esporte, Universidade de São Paulo;

***Universidade Presbiteriana Mackenzie.

Embora no Brasil o judô possua tradição olímpica, pouco se conhece sobre os aspectos que contribuem para o desenvolvimento do talento no cenário nacional. Sendo assim, o objetivo do presente estudo foi analisar os fatores de apoio psicossocial presentes no desenvolvimento de judocas brasileiros talentosos do sexo masculino. Para tanto, se utilizou uma amostra de seis judocas, pertencentes à seleção brasileira nos Jogos Olímpicos de Atenas, 2004. A pesquisa foi constituída através de um delineamento qualitativo, que utilizou como instrumento uma entrevista composta por três perguntas abertas. Para a análise dos resultados foi utilizado o "Discurso do Sujeito Coletivo". Os discursos indicaram a importância dos fatores relacionados : a) ao apoio da família; b) ao prazer pela prática; e c) a determinação dos judocas, corroborando com a literatura internacional no que tange a relevância dos fatores psicossociais para 0 desenvolvimento do talento em diferentes domínios do conhecimento.

UnIteRmos: Judô; Atletas talentosos; Ambiente de desenvolvimento.

\section{Introdução}

O esporte de alto nível tem sido considerado por diversos autores como um fenômeno dinâmico e complexo, cujo desempenho é decorrente de características multifatoriais (Аввотт \& Collins, 2004; BÖHME, 2002; Hohmann \& Seidel, 2003; Massa, 1999).

Quanto ao desempenho de alto nível observado em diferentes domínios do conhecimento, o treinamento parece ser um aspecto determinante para a aquisição da excelência. Estudos realizados na música (ERICSSON, KRAMPE \& TesCH-RÖMER, 1993; Howe, 1999), no xadrez (CHASE \& SimON, 1973; DE Groot, 1978), no futebol e no "hokey" (Helsen, Starkes \& Hodges, 1998) e em atletas de luta greco-romana - "wrestlers" - (HodgES \& STARKES, 1996) reportam uma relação direta entre o tempo de treinamento acumulado e o desempenho atingido. Com base nesta relação, Ericsson e Charness (1994), Ericsson e Crutcher (1990), Ericsson, Krampe e Tesch-Römer (1993) e Ericsson e Smith (1991) têm proposto a Teoria da Prática Deliberada que defende a ideia de que, independentemente da predisposição genética, o desempenho de alto nível depende de fatores associados à dedicação, ao esforço e ao prazer do praticante durante, no mínimo, 10 anos de treinamento estruturado.

Neste sentido, é possível verificar na literatura relacionada ao talento, ao talento esportivo, ao treinamento a longo prazo (TLP) e ao desempenho esportivo, a relevância atribuída por diferentes autores aos aspectos psicossociais (BLOOM, 1985; Böhme, 1996; Csikszentmihalyi, Rathunde \& Whalen, 1997; De Rose Junior, 1993; Ericsson, Krampe \& Tesch-Römer, 1993; VissCher, 2004).

Conforme Moraes, Durand-Bush e Salmela (1999), além do treinamento, o sucesso de uma pessoa talentosa depende do seu comprometimento, motivação e paixão pela sua área de atuação e, ao mesmo tempo, do apoio de diversos segmentos da sociedade como, a própria família, bons mentores e professores e também bons treinadores no caso do esporte.

Para BöHME (2002), motivação, disponibilidade para o desempenho, esforço e estabilidade psicológica são apontados como componentes psicológicos do talento esportivo. 
De acordo com Silva e Rúbio (2003), a história de vida de atletas brasileiros medalhistas olímpicos possui um discurso marcado por indicações de persistência e perseverança diante dos obstáculos inerentes ao processo de treinamento e competiçôes.

Ferreira, Markunas e Nascimento (2004) comentam que durante o processo de formação esportiva se deve considerar na preparação psicológica, o controle emocional em treinamento e competições, a busca de níveis adequados de concentração e técnicas de controle de estresse e ansiedade, bem como um programa que se ocupe inclusive da avaliação, acompanhamento e formação da identidade profissional dos atletas.

Para STARKes (2000), o sucesso do processo de treinamento consiste em manter o atleta potencialmente motivado, competitivo e envolvido o suficiente para adquirir a prática necessária que o conduzirá ao alto desempenho.

Sendo assim, MARKUNAS (2005) salienta que os aspectos psicológicos do desenvolvimento de talentos esportivos se referem àquelas características e fatores emocionais, cognitivos e psicossociais presentes no treinamento a longo prazo, tais como motivação e apoio social (da família ao treinador, entre outros) e também prazer e alegria, expressando o nível de satisfação presente nos processos de desenvolvimento.

Neste sentido, Côté (1999) realizou um estudo acerca da influência da família no desenvolvimento do talento no esporte. Os resultados indicaram que entre os seis e 13 anos de idade os familiares geravam oportunidades e despertavam o interesse das crianças pela prática esportiva. Além disso, as crianças e suas famílias também participavam de atividades esportivas extracurriculares, experimentando de maneira prazerosa a uma variedade de opções de prática.

Conforme Vieira e Vieira (2001), em um estudo realizado com atletas paranaenses de atletismo, durante os anos iniciais da aprendizagem, as crianças se interessavam pela prática de atividades motoras sobretudo pelo incentivo do pai $(21,4 \%)$ ou de irmãos que também praticavam atletismo $(57,1 \%)$.

Um estudo retrospectivo realizado em Israel por LIDOR e LAVYAN (2002), com atletas de elite provenientes de 21 modalidades esportivas e entre elas o Judô, verificou que a família (48\%), os amigos (13\%) e os professores de educação física (11\%) foram fundamentais para o envolvimento da criança com a modalidade. Ademais, os resultados indicaram que a maioria das famílias oferecia suporte $(71 \%)$ para a criança participar dos programas de treinamento, tanto financeiro (55\%) quanto emocional (45\%). Em relação aos fatores motivacionais, a principal fonte era a intrínseca (87\%).
Neste sentido, em um estudo realizado por HolT e Morley (2004) foram observados os fatores psicossociais associados ao sucesso esportivo durante os anos da infância. Entre outros resultados, se pode destacar a influência que pai e irmãos (35,9\%), oportunidades na escola $(20,5 \%)$ e eventos esportivos (12,8\%) exerceram sobre a escolha da modalidade esportiva pela criança. Quanto aos motivos que levaram as crianças a participarem da modalidade escolhida, o prazer pela atividade $(61,5 \%)$ e pela competição $(30,8 \%)$ foram os fatores mais apontados. Os suportes emocionais da família $(53,8 \%)$ e de professores (10,3\%) também se manifestaram como fatores relevantes para a participação da criança no treinamento esportivo.

Em um amplo estudo realizado por GiBBONS, Hill, McConnell, Forster e Moore (2002) entre os anos de 1984 e 1998, sobre o processo de desenvolvimento de 816 atletas olímpicos norteamericanos, foi aplicado um questionário intitulado "Questionário de Identificação e Desenvolvimento do Talento". Entre outros resultados obtidos, foi possível verificar que a maioria dos atletas olímpicos começou a sua formação em comunidades locais que geravam oportunidades de prática, revelando a importância que programas esportivos descentralizados podem exercer nos anos iniciais da aprendizagem. A exemplo dos estudos anteriormente citados, nos anos iniciais da aprendizagem, a ênfase adotada nos programas esportivos era sobre a prática prazerosa e divertida, fazendo com que o amor ao esporte cultivado neste período gerasse o motivo principal para a continuidade da criança nas demais fases do TLP.

Ademais, foi possível verificar nos atletas olímpicos norte-americanos, que o amor ao esporte e a influência dos familiares e técnicos exerceram importância sobre o encaminhamento esportivo na modalidade escolhida. Quanto aos fatores que motivaram os atletas a participarem da modalidade, o amor pela competição, o divertimento, o desejo pelo sucesso, competir em outras cidades e outros valores intrínsecos se revelaram como preponderantes para o desenvolvimento do talento. Por sua vez, os fatores de maior impacto na permanência durante o processo de TLP foram a dedicação e o compromisso, o foco mental, o sucesso competitivo, a família, os treinadores, os colegas de treinamento, entre outros. Por outro lado, conflitos com trabalhos paralelos, suporte financeiro deficitário, tempo escasso, lesões e pressão dos parentes fomentaram os principais motivos para o abandono da prática nos pares dos atletas olímpicos norte-americanos (GibBons et al., 2002). 
Desta maneira, é possível verificar que os resultados encontrados por Côté (1999), Vieira e Vieira (2001), Lidor e LaVyan (2002) e Holt e Morley (2004) corroboram com as colocações de Bloom (1985) e Csikszentmihalyi, Rathunde e Whalen (1997) acerca da importância dos fatores psicossociais

\section{Métodos}

\section{Amostra}

Foi utilizada uma amostra de seis atletas (S1, S2, S3, S4, S5, S6) convocados para compor a seleção olímpica masculina de judô nos Jogos Olímpicos de Atenas, 2004 e que concordaram em participar da pesquisa. Conforme a aprovação do projeto junto ao Comitê de Ética em Pesquisa da EEFE-USP, os judocas assinaram Termo de Consentimento Livre e Esclarecido.

\section{Procedimentos}

Foi utilizado como instrumento de pesquisa o método do "Discurso do Sujeito Coletivo" (DSC), LeFÈVRE e LeFÈVRE (2003). O DSC permitiu uma abordagem qualitativa acerca do processo de iniciação de judocas olímpicos brasileiros. Conforme LeFÈVRE e LEFÈVRE (2003), o pensamento é algo essencialmente discursivo e só pode ser obtido numa escala coletiva a partir de perguntas abertas elaboradas para um conjunto de indivíduos de alguma forma representativos dessa coletividade, deixando com que esses indivíduos se expressem mais ou menos livremente, ou seja, que produzam discursos. Neste sentido, a questão fechada seria insuficiente diante dessa perspectiva, pois não ensejaria a expressão de um pensamento, mas a expressão de uma adesão (forçada) a um pensamento preexistente.

A metodologia do DSC utilizada é, portanto, uma proposta de organização e tabulação de dados qualitativos de natureza verbal e, no presente estudo, nos anos iniciais da aprendizagem e durante o processo de desenvolvimento do talento. Portanto, diante da relevância atribuída a estes aspectos, o objetivo do presente estudo foi analisar os fatores de apoio psicossocial presentes no desenvolvimento de judocas brasileiros talentosos do sexo masculino.

obtidos de depoimentos dos atletas. Para confeccionar os DSCs, LEFÈVRE e LEFÈvRE (2003) criaram as seguintes figuras metodológicas:

a) Expressões-chave $(\mathrm{ECH})$ : transcrições literais do discurso. Desta maneira as ECH são a matériaprima do DSC.

b) Ideias centrais (IC): é um nome ou expressão linguística que revela e descreve, de forma sintética, precisa e fidedigna, o sentido de cada um dos discursos analisados e de cada conjunto homogêneo de $\mathrm{ECH}$, que vai dar origem, posteriormente, ao DSC. Observação: cada discurso individual pode conter uma ou mais IC.

c) Discurso do Sujeito Coletivo (DSC): é um discurso síntese redigido na primeira pessoa do singular e composto pelas ECH que têm a mesma IC. Ou seja, o DSC é a soma das ECH de cada discurso individual que possui a mesma IC. Para maiores esclarecimentos, vide LEFÈVRE e LEFÈvre (2003).

Assim, foi utilizado um roteiro de entrevista composto por três perguntas:

1) Vocêpode me contar o que te fez manter o tempo todo o teu interesse no judô?

2) Me conte como era a participação dos seus pais, familiares e amigos em relação ao judô.

3) Toda competição é meio estressante não é? Como era isso para você?

Os depoimentos foram gravados em fita magnética e, posteriormente, transcritos de modo a recuperar a integridade dos mesmos, servindo de matéria prima para a construção do DCS.

\section{Resultados}

Diante da possibilidade de verificar quais fatores foram relevantes para aderência dos judocas ao TLP, é que foi elaborada a pergunta - Vocêpode me contar o que te fez manter o tempo todo o teu interesse no

judô? - . Neste sentido, em relação à referida pergunta, seguem apresentadas na TABELA 1 as ideias centrais (IC) captadas, a frequência das respostas e o percentual referente a cada IC. 
TABELA 1 - Caracterização das ideias centrais, frequência e percentual de respostas para a pergunta: Você pode me contar o que te fez manter o tempo todo o teu interesse nojudô?

\begin{tabular}{llcc}
\hline & \multicolumn{1}{c}{ IC } & Frequência & \% \\
\hline A & Amor e prazer & 3 & 50,0 \\
B & Profissionalismo & 1 & 16,6 \\
C & Determinação & 3 & 50,0 \\
D & Apoio da família & 2 & 33,3 \\
E & Viagens & 1 & 16,6 \\
\hline
\end{tabular}

Assim, as cinco ICs captadas (IC-A, IC-B, ICC, IC-D e IC-E) e apresentadas na TABELA 1, emergiram do DSC construído a partir do discurso individual dos judocas, configurando o DSC1, DSC2, DSC3, DSC4 e DSC5.

\section{DSC1: IC-A - Amor e prazer (S1, S2, S5)}

No início e no meio foi por amor ao esporte mesmo, sempre gostei muito do Judô. Acho que até hoje eu estou aqui porque eu amo o Judô, o que eu faço, o sonho de poder ouvir o Hino Nacional e poder representar o Brasil, eu acho que no Judô isso é o que mais conta.

\section{DSC2: IC-B - Profissionalismo (S5)}

Obs.: o discurso se refere exclusivamente ao sujeito $S 5$, pois apenas ele apresentou a IC profissionalismo, não caracterizando, portanto, um discurso coletivo.

Depois dos 21 anos, depois do título do campeonato mundial, eu fazia Judô como se fosse profissional, tinha patrocínio, tinha quem me bancava e foi isso que foi me levando até hoje.

\section{DSC3: IC-C - Determinação (S1, S2, S6)}

\footnotetext{
Eu tenho objetivos a serem concretizados, então isso que me estimula. Como treinamos muito, a única coisa que levamos é a honra de estar defendendo o país, de estar defendendo a família, fazendo tudo para estar bem no tatame. Então esse foi o sonho, o combustível para que eu mesmo, com tantas derrotas, nunca desistisse do meu sonho, pois se outros chegaram eu também posso chegar. Eu ainda não consegui tudo e isso me motiva.
}

\section{DSC4: IC-D - Apoio da família (S3, S6)}

Já desde pequeno meus pais sempre me apoiavam. As vezes eu até jogava um pouquinho de futebol em um clube, até chegava machucado e meu pai me dava bronca, ele não gostava, ele queria que eu fizesse Judô. Teve um momento que eu queria parar, foi na época que eu tinha 13 para 14 anos, foi um momento crítico na minha carreira, onde acho que até os 12 anos eu fazia meio que empurrado. Depois queria parar, acho que a peça fundamental foi a minha mãe. Acho que minha mãe foi uma das pessoas que mais me estimularam, mais me estimulou em toda a minha carreira, desde minha parte inicial até a parte quando me destaquei. Então se não fosse ela, mesmo tendo um potencial, até treinando, se não fosse ela eu teria largado muito cedo.

\section{DSC5: IC-E - Viagens (S4)}

Obs.: o discurso abaixo se refere exclusivamente ao sujeito S4, pois apenas ele apresentou a IC viagens, não caracterizando, portanto, um discurso coletivo.

Eu acho que o que me fez manter no Judô tanto tempo foi a oportunidade de tentar ganhar as competições e poder fazer as viagens. Acho que isso que me fez me manter no Judô, que realmente eu não gostava de quando comecei. Não gostava de praticar Judô, mas a oportunidade de eu poder ir participar em um outro Estado, uma outra cidade, essa oportunidade de ir viajar sem os pais acabou fazendo com que eu pegasse gosto por campeonato. Depois chegou a minha adolescência e eu realmente comecei a ganhar as competiçôes e conhecer outros países.

Acerca das demais relações que envolvem o cotidiano do judoca, surge o questionamento sobre a extensão das relações sociais do judoca com outros membros da sociedade e, inclusive, sobre o teor dessas possíveis relações com o universo de desenvolvimento do judoca durante o TLP.

Desta maneira, diante da possibilidade de verificar a interação das relações sociais dos judocas durante o TLP, foi elaborada a pergunta - Me conte como era a participação dos seus pais, familiares e amigos em relação ao judô - . Neste sentido, seguem apresentadas na TABELA 2 as ICs captadas, a frequência das respostas e o percentual referente à cada IC. 
TABELA 2 - Caracterização das ideias centrais, frequência e percentual de respostas para a pergunta: Me conte como era a participação dos seus pais, familiares $e$ amigos em relação ao judô.

\begin{tabular}{|c|c|c|c|}
\hline & IC & Frequência & $\%$ \\
\hline A & Apoio da família & 6 & 100,0 \\
\hline B & Descrença dos familiares & 1 & 16,6 \\
\hline $\mathrm{C}$ & $\begin{array}{l}\text { Ambiente do judô e } \\
\text { amigos }\end{array}$ & 3 & 50,0 \\
\hline
\end{tabular}

Assim, as três ICs captadas (IC-A, IC-B e IC-C) e apresentadas na TABELA 2, emergiram do DSC construído a partir do discurso individual dos judocas, configurando o DSC1, DSC2 e DSC3.

\section{DSC1: IC-A - Apoio da família (S1, S2, S3, S4, S5, S6)}

Meu pai e minha mãe nunca me forçaram a trabalhar. Tínhamos muitas dificuldades, mas nem por isso eles falavam para eu parar de fazer Judô. Muito pelo contrário, meus pais sempre me estimularam. O Judô infelizmente é um esporte que não tem muito apoio, não tem muito retorno, então tive muito apoio da família mesmo. Minha mãe, para me incentivar quando era criança, também entrou no Judô e acho que a parte melhor é que eles nunca me cobraram resultados, eles sempre me apoiavam. O meu pai nunca mediu esforços para me ajudar. Ele começou a acompanhar muito o Judô e se interessou pela modalidade. Nós discutíamos muito dentro de casa o que tinha que melhorar, até incentivo financeiro, incentivo emocional, sempre viajando nas competições que podia e mesmo quando não podia sempre motivando, mesmo quando distante. Sempre falando que eu tinha oportunidade, que eu tinha condiçōes de conquistar um espaço, de realizar sonhos. Então eu acho que grande parte da minha conquista se deve muito a minha família. Pelo incentivo, porque no esporte caímos muito, deslizamos, e a família sempre por trás dando suporte. Judô é isso mesmo, é família, é companheirismo e sem essa família, sem essa comunhão social de todo mundo, nada seria possível no Judô.

\section{DSC2: IC-B - Descrença dos familiares (S3)}

Obs.: o discurso abaixo se refere exclusivamente ao sujeito $S 3$, pois apenas ele apresentou a IC descrença dos familiares, não caracterizando, portanto, um discurso coletivo.
Meus tios, avós e outros familiares falavam para eu parar de fazer Judô, que Judô não dava camisa para ninguém. Todo mundo pensava que Judô era uma briga e muitos criticavam. Diziam que Judô não dá em nada, não dá futuro para ninguém. Tinham essa mentalidade.

\section{DSC3: IC-C - Ambiente do judô e amigos (S4, S5, S6)}

No colégio o pessoal já respeitava a modalidade que eu fazia e dentro do Judô sempre foi uma harmonia muito grande. Eu acho que o Judô é o único esporte que se fazem amigos, não se fazem inimigos. Dentro do tatame e fora todo mundo ficou amigo, então eu tenho certeza que nunca tive problemas após o tatame. Em relação à amizade, acho que todos os meus grandes amigos são do Judô, a grande maioria é do Judô, um vai apoiando o outro. Desde o início e até hoje todos são meus amigos, todos praticam Judô e isso me deu suporte para continuar competindo.

Desta maneira, de acordo com os resultados dos DSCs apresentados, pode-se verificar conforme a TABELA 2, a relevância da família $(n=6)$ e do próprio ambiente do judô e amigos $(n=3)$ para os judocas. Em contrapartida, mesmo se tratando de um DSC registrado a partir de um único sujeito da amostra $(\mathrm{S} 3)$, pode-se observar no DSC2 que a descrença dos demais familiares pode se tornar um fator potencialmente comprometedor do processo de desenvolvimento do talento.

Com o intuito de verificar a interferência do estresse competitivo em judocas olímpicos brasileiros, é que foi elaborada a pergunta - Toda competição é meio estressante não é? Como é isso para você? -. Desta forma, seguem apresentadas na TABELA 3 as ICs captadas, a frequência das respostas e o percentual referente a cada IC.

TABELA 3 -Caracterização das ideias centrais, frequência e percentual de respostas para a pergunta: Toda competição é meio estressante não é? Como é isso para você?

\begin{tabular}{|c|c|c|c|}
\hline \multicolumn{2}{|r|}{ IC } & Frequência & $\%$ \\
\hline A & Estresse, ansiedade & 5 & 83,3 \\
\hline B & $\begin{array}{l}\text { Motivação, superação, } \\
\text { confiança }\end{array}$ & 6 & 100,0 \\
\hline
\end{tabular}

Assim, as duas ICs captadas (IC-A e IC-B) e apresentadas na TABELA 3, emergiram do DSC construído a partir do discurso individual dos judocas, configurando o DSC1 e o DSC2. 


\section{DSC1: IC-A - Estresse, ansiedade (S1, S2, S3, S4, S5)}

Quando você é jovem e não tem um calendário cheio de competições você acaba encarando numa boa. A partir do momento que a competição passa a ser uma em cima da outra é que acaba sendo maçante. Não pelo corpo, mas pela cabeça. Acho que cansa porque a competição tem toda uma preparação mental, você se prepara, você se concentra e você sempre acaba cansando. Até hoje sinto aquele frio na barriga e tenho que ir ao banheiro todas as lutas antes para liberar um pouco a adrenalina. Eu acho que quando o atleta objetiva uma posição alta não tem como não sentir um certo receio. Eu conseguia lidar com essas situações de cobrança. Lógico, ficava com ansiedade, mas eu conseguia administrar um pouco mais isso, e mostrar que não posso dar branco. Atualmente, para não passar mais por isso, estou tentando voltar às minhas origens. Ou seja, estou tentando tirar um pouco do peso da responsabilidade que está presente em cada competição. Antes, tive momentos que acabei me cobrando demais e não me saí tão bem quando quis vencer todos por “ippon”. Eu vi que não é assim, você tem que acabar deixando o trabalho fluir. Nos últimos anos eu senti um pouco mais. Depois que você adquire um título a medalha acaba pesando um pouquinho. No meu caso pesou bastante. Comecei a competir querendo apenas jogar de “ippon” e ganhar. Então nesses últimos anos comecei a me machucar bastante, eu comecei a sentir muito o peso disso, que hoje eu sei que me fez mal, tanto é que eu estou parado faz um ano afastado de competição, devido a isso).

\section{Discussão}

Conforme Ericsson e Charness (1994), com o progresso e o acúmulo do conhecimento científico, tornou-se gradualmente mais evidente que os indivíduos poderiam aumentar o seu desempenho através da educação e do treinamento, se tivessem motivação, objetivo e direcionamento.

Neste sentido, de acordo com JocH (1994) citado por BÖHme (2000) e Moraes, Durand-Bush e SALMELA (1999), o sucesso de uma pessoa talentosa depende do seu comprometimento, motivação e paixão pela
DSC2: IC-B - Motivação, superação, confiança (S1, S2, S3, S4, S5, S6)

No início eu ia para competição com aquele gelo na barriga. Eu acho que é isso que motiva o atleta a estar competindo, mas eu tinha prazer, era um estresse tolerável, um estresse gostoso de se sentir. Nestes últimos dias estive viajando e competindo em vários lugares diferentes e agora estou aqui competindo de novo; eu estou meio cansado, então tenho que tirar motivação lá de dentro e imaginar o meu objetivo para me estimular e tirar proveito de toda competição. $\mathrm{O}$ vitorioso é aquele que transforma esse receio em combustível para que ele alcance o seu objetivo. Então eu acho que é uma virtude que eu tenho. Eu treinava 24 horas, eu pensava 24 horas nos meus adversários, às vezes pensava mais neles do que na minha família inteira. Uma coisa que a imprensa sempre destacou em mim é meu jeito frio de competir. Eu estou sempre na minha, ganhando ou perdendo não me deixo afetar e me concentro no que estou fazendo. Se o árbitro tiver errando e eu estiver perdendo, estarei sempre do mesmo jeito e vou procurar vencer o cara do meu jeito. Hoje em dia também tenho tentado resgatar o prazer que me trouxe ao Judô, procurando aproveitar cada momento com mais tranquilidade. Procuro lutar por amor ao esporte que eu sempre fiz, e como eu não vou ter patrocínio, eu não vou ter um clube por trás me cobrando, eu acho que vai ser até mais fácil para mim agora).

Assim, de acordo com os resultados expressos na TABELA 3, pode-se verificar que os judocas olímpicos brasileiros apresentam características de estresse e ansiedade (DSC1: 83,3\%; $\mathrm{n}=5$ ) e de motivação, superação e confiança (DSC2: 100\%; n = 6).

sua área de atuação e, inclusive, do apoio de diversos segmentos da sociedade, sobretudo a própria família.

Desta maneira, de acordo com os resultados dos DSCs apresentados, pode-se verificar conforme a TABELA 1 , que a presente amostra aderiu ao treinamento no judô devido a fatores como: amor e prazer (50\%), determinação $(50 \%)$, apoio da família $(33,3 \%)$, profissionalismo (16,6\%) e acesso a viagens (16,6\%).

No DSC1 (amor eprazer) e no DSC3 (determinação), corroborando com GiBBONs et al. (2002), é possível 
verificar a presença do desejo revelado de querer chegar ao topo do desempenho. Embora no DSC1 conste de forma marcante o fator do prazer e do amor pela prática, sobretudo nos anos iniciais e intermédios da aprendizagem, pode-se observar que o desejo pela conquista é a recompensa que impulsiona o sujeito a se manter na atividade. Tal constatação é evidenciada no DSC3, onde a determinação pela busca do melhor resultado supera momentos de derrota encontrados durante o percurso. Ou seja, mesmo diante de possíveis dificuldades e derrotas o judoca se manteve aderente ao processo, pois possuía como meta irrevogável o alcance do mais alto desempenho.

Desta forma, os resultados parecem se aproximar dos trabalhos de Аввотт e Coluins (2004), BÖHME (2004) e ERICSSON e CHARNESS (1994), sobretudo em relação às considerações elaboradas sobre os estudos pioneiros de Francis Galton no século XIX, sendo o primeiro cientista a investigar empiricamente a possibilidade de que o comportamento/excelência em distintos campos e domínios tivesse uma série comum de causas decorrentes de características inatas. Um exemplo disso foi a utilização da antropometria para determinação de pessoas criminosas. Contudo, através da análise de homens eminentes e seus parentes, numa ampla variação de domínios, Francis Galton argumentou que três fatores devem estar presentes: capacidade inata, ânsia para trabalhar e um poder adequado de fazer muito trabalho laborioso. Posteriormente, devido à importância dos dois últimos fatores motivação e esforço - os investigadores concentraramse em demonstrar que apenas primariamente as capacidades e talentos inatos são necessários para o alcance dos mais altos níveis de desempenho.

Portanto, afora a inquietação acerca da decorrência inata e/ou adquirida do talento (ERICSSON \& CHARNESS, 1994; HowE, 1999), a motivação para se manter aderente ao estudo/treinamento numa determinada área de conhecimento parece ser um elemento fundamental para o desenvolvimento do talento.

Neste sentido, assim como no presente trabalho, no estudo de GibBOns et al. (2002), atletas olímpicos norte americanos apontaram o amor pela competição, a prática prazerosa e o desejo pela conquista do sucesso esportivo como os principais fatores de motivação e aderência ao esporte.

Em relação ao DSC4 (apoio da família), é possível notar que a força de apoio da família, foi fundamental para a permanência do judoca na modalidade. Conforme o DSC4, em alguns momentos do processo de TLP, sobretudo na faixa etária do início da adolescência, a vontade presente no judoca era de parar os treinamentos no judô. Ademais, é contundente no DSC4 o reconhecimento de que mesmo havendo potencial para o alto desempenho na modalidade, o judoca pensava em abandonar a prática. Entretanto, por efeito do apoio da mãe, o mesmo acabou permanecendo na modalidade. Portanto, o apoio da família ilustra os discursos dos judocas no sentido de exercer papel fundamental para o desenvolvimento do talento, contribuindo para o processo de iniciação e permanência na modalidade.

Neste sentido, os DSCs 1 e 3 parecem incorporar as ideias de Ericsson, Krampe e Tesch-Römer (1993) a respeito da restrição de motivação, que se refere ao reconhecimento de que o processo de treinamento não é inerentemente prazeroso ou imediatamente recompensado. De acordo com os DSCs 1 e 3, nos anos iniciais e intermédios da aprendizagem o prazer pela prática era a grande motivação do judoca, mas no decorrer do processo a determinação de poder chegar ao alto nível de desempenho passou a ser o fator relevante que motivava o judoca a permanecer nos treinamentos. Conforme ERICSSON, Krampe e Tesch-RÖMER (1993), jovens talentosos se mantêm motivados diante do processo em função da percepção de que a prática deliberada, mesmo não oferecendo necessariamente uma recompensa imediata, pode oferecer um apoio instrumental extremamente representativo para a evolução em direção ao alto desempenho.

Por sua vez, BLOOM (1985) destaca a importância das fontes de motivação e recompensa, bem como das circunstâncias especiais de encorajamento e suporte para o indivíduo em diferentes estágios do seu desenvolvimento. Como foi observado no DSC2 (profissionalismo), o judoca adulto e com resultados expressivos na modalidade, manteve-se profissionalmente aderente ao judô devido à recompensa e ao suporte do patrocinador que financiava não somente as condições para a prática, mas também o salário do judoca. Em relação ao DSC5 (viagens), alguns judocas se mantinham aderentes à modalidade, além dos fatores anteriormente citados, por circunstâncias relacionadas a fontes externas de motivação e recompensa. Ou seja, a percepção de que competindo no judô seria possível viajar pelo Brasil e até pelo mundo, trazia ao judoca uma componente que por vezes ultrapassava o próprio prazer em praticar a modalidade.

Portanto, é possível verificar que os fatores acima destacados se aproximam dos elementos fundamentais apresentados por BloOm (1985), CsiKsZENTMIHALYI, Rathunde e Whalen (1997), Ericsson, Krampe e Tesch-RÖMER (1993), ERICSSON e CHARNEss (1994), 
Gibbons et al. (2002) e Moraes, Durand-Bush e Salmela (1999), no que tange à importância da motivação e das forças de apoio para a participação do sujeito no processo de desenvolvimento de talentos.

Neste sentido, o DSC2 (descrença dos familiares) carrega em seu bojo a desvalorização social a respeito da prática do judô. Tal desvalorização sociocultural pode estar sendo fomentada por preconceitos de rejeição à modalidade, gerados pela desconfiança sobre o valor social do judô.

Sendo assim, pode-se inferir sobre o impacto negativo que esse pensamento poderia gerar quando associado não somente aos familiares, mas também aos pais e amigos do sujeito (SimôEs, BöHmE \& LUCATO, 1999). Isto é, suportar a prática de uma determinada atividade por tanto tempo quando ao seu lado não há ninguém que ofereça reforço e valorização é, supostamente, um desafio muito maior do que estar envolvido num contexto onde pais, familiares e amigos participem positivamente do seu envolvimento na atividade.

Neste sentido, conforme BöHME (2004), devese atentar para as condiçốes sociais limitantes do desempenho esportivo que estão presentes, entre outros fatores, nas atitudes da sociedade em relação ao desempenho e no valor que a modalidade esportiva possui na sociedade.

Não obstante, o presente estudo confirma que a totalidade dos judocas entrevistados (DSC1) manifestou o peso positivo da família durante o processo de desenvolvimento do talento. Tal manifestação pode ser sintetizada pelo pensamento expresso na frase “...Judô é isso mesmo, é família, é companheirismo e sem essa família, sem essa comunhão social de todo mundo, nada seria possível no Judô", no qual a importância da congruência da família em relação ao judô é marcante.

Ademais, o DSC3 (ambiente do judô e amigos) traz uma característica interessante sobre o ambiente social de desenvolvimento do judoca. Conforme o DSC3, embora seja possível notar que não há no discurso a presença de elementos que demonstrem um grande número de amigos fora do judô, o que poderia ser socialmente negativo; existe, por outro lado, a presença de um discurso que indica a peculiaridade do ambiente de desenvolvimento dos judocas, sendo que dentro do próprio judô conseguiram constituir amizades que ultrapassaram os limites do tatame.

Assim, nota-se no DSC3 que os grandes amigos mantidos desde a infância até a idade adulta e que deram suporte uns aos outros para a permanência $e$ evolução na modalidade foram os próprios judocas, que mesmo sendo adversários de tatame souberam compartilhar os obstáculos do processo de treinamento no judô, das competições e das seletivas sem deixar a competitividade por uma vaga interferir na relação de amizade. Neste sentido, cabe salientar que a história, a tradição e a filosofia de harmonia e respeito ao ser humano com a qual o judô é desenvolvido (Deliberador, 1996; Monteiro, 1998), pode ter auxiliado na manutenção do companheirismo e da amizade entre os judocas, cultivando um ambiente particularmente interessante para o processo de desenvolvimento do talento.

Portanto, a reunião das características observadas no DSC1 (apoio da família) e no DSC3 (ambiente do judô e amigos), formou um dueto social coeso e positivo para o judoca durante o seu processo de desenvolvimento. Em outras palavras, mesmo diante da pouca valorização que o judô pode estar sofrendo na cultura da sociedade em geral, esse dueto funcionou como um microssistema capaz de potencializar as condições sociais necessárias para o desempenho, gerando cultura suficiente para que as famílias agregadas construíssem o suporte e as perspectivas de uma nova geração de judocas.

Conforme Bloom (1985) e Csikszentmihalyi, Rathunde e Whalen (1997), no esporte e na arte fatores negativos inerentes à competição ocorrem em detrimento do processo de desenvolvimento de alguns jovens promissores.

Desta maneira, é possível notar no DSC1 (estresse e ansiedade) que o desgaste psicológico necessário para o preparo mental diante de uma competição é muito intenso. Além disso, situações decorrentes da pressão por melhores resultados, das seletivas, dos patrocinadores, entre outros fatores, eram capazes de gerar, inclusive, a queda do desempenho competitivo do judoca.

Portanto, assim como nos estudos de BloOM (1985), Csikszentmihalyi, Rathunde e Whalen (1997) e Ericsson, Krampe e Tesch-Römer (1993), a trajetória de desenvolvimento dos judocas investigados nem sempre esteve necessariamente associada a experiências prazerosas. Ou seja, situações negativas oriundas do processo de desenvolvimento do talento podem contribuir para uma mudança do estadode-espírito dos judocas, fazendo com que o prazer pela prática dê lugar ao sentimento de repulsa, com extensões psicológicas que capazes de gerar índices elevados de desistência do processo de TLP no judô.

Neste sentido, é notável no DSC1 o discurso do judoca que por efeito dos fatores anteriormente citados (ex.: cobrança por melhores resultados, patrocinadores, entre outros) se manteve afastado 
do judô por um período de um ano e somente mais recentemente, com o devido controle dos agentes geradores do estresse psicológico negativo, está pensando em retomar as atividades competitivas.

Neste sentido, conforme MARQues (1991) e WeINECK (1999), procedimentos equivocados durante a fase de promoção do talento, podem fazer com que o jovem atleta abandone a prática esportiva pela saturação psicológica, devido a quantidades inadequadas e exaustivas de treinamento e a alta exigência em competições.

Em contrapartida, o DSC2 (motivação, superação e confiança) demonstra que mesmo diante de situaçôes de estresse e ansiedade, os judocas conseguiram se superar diante dos obstáculos inerentes ao processo de TLP e competições, se mantendo na atividade. Conforme o DSC2, o estresse se mantinha num grau tolerável, que ainda possibilitava o prazer pela prática. Ou seja, era o estresse positivo gerado pela competição que se manifestava no judoca, permitindo que este entrasse no ambiente da competição e, com a devida

\section{Considerações finais}

Os resultados da presente pesquisa indicam que o prazer, a determinação e o apoio da família exerceram grande influência para a aderência do judoca ao processo de treinamento a longo prazo. Estes achados corroboram com os pressupostos motivacionais apontados pela literatura como relevantes para o processo de desenvolvimento do talento.

Quanto às relações sociais estabelecidas pelos judocas durante o processo de desenvolvimento na modalidade, foi possível verificar que: 1) o apoio da família (100\%); e 2) o ambiente do judô e amigos (50\%) formaram um dueto social coeso e positivo para o judoca durante o seu processo de desenvolvimento. Em outras palavras, esse dueto funcionou como um microssistema capaz de potencializar as condições sociais necessárias para o desempenho, gerando cultura suficiente para que as famílias agregadas construíssem o suporte e as perspectivas de uma nova geração de judocas.

Em relação aos fatores de estresse e ansiedade, foi verificado que as situações decorrentes da concentração, se preparasse para o alto desempenho competitivo, sobretudo não deixando que os aspectos ressaltados no DSC1 prevalecessem diante do processo e prejudicassem o desempenho competitivo.

Sendo assim, a exemplo do "O Fluxo de Experiência Ótima” citado por CsiKsZENTMIHALYI, RATHUNDE e WHALEN (1997), o presente estudo parece coerente com a ideia de que: a) nenhum adolescente desenvolverá talentos se não se divertir trabalhando e, ao mesmo tempo; b) nenhum adolescente poderá evitar os conflitos inerentes ao desenvolvimento do talento. Neste sentido, contar com a força de apoio adequada de pais e técnicos parece ser fundamental para o suporte do adolescente diante do processo de TLP, pois nem sempre o mesmo será automaticamente prazeroso. Portanto, o apoio dos pais e de técnicos devidamente preparados se faz necessário para que se possam gerar situações que estimulem os jovens a continuarem motivados diante dos desafios crescentes decorrentes do processo de detecção, seleção e promoção de talentos esportivos.

pressão por melhores resultados, das seletivas, dos patrocinadores, entre outros fatores, foram capazes de gerar, inclusive, a queda do desempenho por parte de alguns judocas. Portanto, corroborando com a literatura, a trajetória de desenvolvimento dos judocas investigados nem sempre esteve necessariamente associada a experiências prazerosas. Ou seja, situações negativas oriundas do processo de desenvolvimento do talento podem contribuir para uma mudança de comportamento, com extensões psicológicas capazes de gerar índices elevados de desistência no judô, podendo comprometer o êxito do processo de desenvolvimento do talento. Por outro lado, de maneira positiva, a presente amostra de judocas conseguiu demonstrar que mesmo diante de situaçōes de estresse e ansiedade, se superavam diante dos obstáculos inerentes ao processo de TLP e competições, se mantendo na atividade devido a elevados índices de motivação, superação e confiança. 


\section{Abstract \\ Olympic judo athletes: psychosocial support elements to sports talent development}

Although judo is a traditional Olympic Sport in Brazil, little is known regarding the key aspects to develop talents at the national scenario. The objective of this study was to analyze the psychosocial supporting factors that are seen in the development of talented male Brazilian Judo athletes. A sample of 6 athletes that were in the Athens Olympic Games of 2004 was studied. Research was designed on qualitative basis and used a three open questions interview as investigative tool. Results were analyzed using the discourse of the collective subject. Discourses indicated as important, factors related to: a) family support; b) pleasure in practice; and c) athletes determination, reinforcing the international scientific literature regarding the importance of psychosocial factors to talent development in several knowledge domains.

UnITERMS: Judo; Talent athletes; Development environment.

\section{Referências}

ABBOTT, A.; COLLINS, D. Eliminating the dichotomy between theory and practice in talent identification and development: considering the role of psychology. Journal of Sports Sciences, London, v.22, p.395-408, 2004.

BLOOM, B.S. Developing talent in young people. New York: Ballentine, 1985.

BÖHME, M.T.S. Detecção, seleção e promoção de talentos esportivos: determinação de critérios de desempenho nos aspectos bio-psico-social. São Paulo: EEFEUSP, 1996. (Projeto de pesquisa interdisciplinar do Departamento de Esporte). . O treinamento a longo prazo e o processo de detecção, seleção e promoção de talentos esportivos. Revista Brasileira de Ciências do Esporte, Porto Alegre, v.21 n.2/3 p. 4-10, 2000.

O talento esportivo e o processo de treinamento a longo prazo. In: DE ROSE JUNIOR, D. (Org.). Esporte e atividade física na infância e na adolescência: uma abordagem multidisciplinar. Porto Alegre: Artmed, 2002. p.109-22. Talento esportivo. In: GAYA, A.; MARQUES, A.; TANI, G. (Orgs.). Desporto para crianças e jovens: razōes e finalidades. Porto Alegre: UFRGS, 2004. p.235-49.

CHASE, W.G.; SIMON, H.A. The mind's eye in chess. In:. CHASE, W.G (Ed.). Visual information processing. New York: Academic Press, 1973.

CÔTÉ, J. The influence of the family in the development of talent in sport. The Sport Psychologist, Champaign, v.13, p.395-417, 1999. CSIKSZENTMIHALYI, K.; RATHUNDE, K.; WHALEN, S. Talented teenagers: the roots of success and failure. Cambridge: Cambridge University Press, 1997.

De GROOT, A. Thought and choice in chess. The Hague: Mouton, 1978. (Original work published 1946.)

De ROSE JUNIOR, D. Importância da preparação psicológica no esporte competitivo. In: SIMPÓSIO PAULISTA DE EDUCAÇÃO FÍSICA, 1993, Rio Claro. Anais... Rio Claro: UNESP, 1993. p.63.

DELIBERADOR, A.P. Judô: metodologia da participação. Londrina: Lido, 1996.

ERICSSON, K.A.; CHARNESS, N. Expert performance: its structure and acquisition. In: CECI, S.J.; WILLIANS, W.M. (Eds.). The nature-nurture debate: the essential readings. Oxford: Blackwell, 1994.

ERICSSON, K.A.; CRUTCHER, R.J. The nature of exceptional performance. In: BALTES, P. B.; FEATHERMAN D.L.; LERNER, R.M. (Eds.). Life-span development and behavior. Hillsdale: Erlbaum, 1990

ERICSSON, K.A.; KRAMPE, R.T.; TESCH-RÖMER, C. The role of deliberate practice in the acquisition of expert performance. Psychological Review, Massachusetts, n.3, 363-406, 1993.

LERNER, R.M. (Eds.). Life-span development and behavior. Hillsdale: Erlbaum, 1990.

ERICSSON, K.A.; SMITH, J. Prospects and limits of the empirical study of expertise: an introduction. In: ERICSSON, K.A.; SMITH, J. (Eds.). Toward a general theory of expertise: prospects and limits. Cambridge: University Press, 1991. FERREIRA, M.C.M.; MARKUNAS, M.; NASCIMENTO, P.R. A prática na formação de atletas no basquetebol feminino. In: De ROSE JÚNIOR, D.; TRICOLI, V. (Orgs.). Basquetebol: uma visão integrada entre ciência e prática. São Paulo: Manole, 2004. 
GIBBONS, T.; HILL, R.; McCONNELL, A.; FORSTER, T.; MOORE, J. The path to excellence: a comprehensive view of development of U.S. Olympians who competed from 1984-1998. Colorado Springs: United States Olympic Committee, 2002. (Initial Report: results of the talent identification and development questionnaire to U.S. Olympians athlete development and coaching and sport sciences divisions, 2002). Disponível em: <http://www.usolympicteam.com/ codp>. Acesso em: 15 dez. 2005.

HELSEN, W.F.; STARKES, J.L.; HODGES, N.J. Team sports and the theory of deliberate practice. Journal of Sport \& Exercise Psychology, Champaign, v.20, p.12-34, 1998.

HODGES, N.J.; STARKES, J.L. Wrestling with the nature of expertise: a sport specifi c test of Ericsson, Krampe and TeschRömer's (1993) theory of “Deliberate Practice”. International Journal of Sport Psychology, Rome, v.27, p.400-24, 1996. HOHMANN, A.; SEIDEL, I. Scientific aspects of talent development. International Journal of Physical Education, Schorndorf, v.40, p.9-20, 2003.

HOLT, N.L.; MORLEY, D. Gender differences in psychosocial factors associated with athletic success during childhood. The Sport Psychologist, Champaign, v.18, p.138-53, 2004.

HOWE, M.J.A. Innate talents: reality or myth? In: CECI, S.J.; WILLIAMS, W.M. (Eds.). The nature-nurture debate: the essential readings. Oxford: Blackwell, 1999.

LEFĖVRE, F.; LEFĖVRE, A.M.C. O discurso do sujeito coletivo: um novo enfoque em pesquisa qualitativa (Desdobramentos). Caxias do Sul: EDUCS, 2003.

LIDOR, R.; LAVYAN, N. A retrospective picture of early sport experiences among elite and near-elite israeli athletes: developmental and psychological perspectives. International Journal of Sport Psychology, Rome, v.33, p.269-89, 2002. MARKUNAS, M. Aspectos psicológicos no desenvolvimento de talentos esportivos. 2005. Dissertação (Mestrado) Escola de Educação Física e Esporte, Universidade de São Paulo, São Paulo, 2005.

MARQUES, A. Da importância das fases iniciais de escolaridade na detecção e selecção de talentos desportivos em Portugal. In: BENTO, J.; MARQUES, A. As ciências do desporto e a prática desportiva: desporto de rendimento, desporto de recreação e tempos livres. Porto: Faculdade de Ciências do Desporto e da Educação Física, Universidade do Porto, 1991. v.2, p.15-21. MASSA. M. Seleção e promoção de talentos esportivos em voleibol masculino: análise de aspectos cineantropométricos. 1999. 154 f. Dissertação (Mestrado) - Escola de Educação Física e Esporte, Universidade de São Paulo, São Paulo, 1999. MONTEIRO, L.B. O treinador de judô no Brasil. Rio de Janeiro: Sprint, 1998.

MORAES, L.C.; DURAND-BUSH, N.; SALMELA, J.H. Modelos de desenvolvimento de talentos. In: SAMULSKI, D.M. (Ed.). Novos conceitos em treinamento esportivo. Belo Horizonte: Publicaçóes INDESP, 1999. p.173-90.

SILVA, M.L.; RÚBIO, K. Superação no esporte: limites individuais ou sociais? Revista Portuguesa de Ciências do Desporto, Porto, v.3, n.3, p.69-76, 2003.

SIMÓES, A.C.; BÖHME, M.T.S.; LUCATO, S. A participação dos pais na vida esportiva dos filhos. Revista Paulista de Educação Física, São Paulo, v.13, n.1, p.34-45, 1999.

STARKES, J.L. The road to expertise: is practice the only determinant? International Journal of Sport Psychology, Rome, v.7 p.23-7, 2000.

VIEIRA, L.F.; VIEIRA, J.L.L. Talentos esportivos: estudo dos atributos pessoais dos atletas paranaenses do atletismo. Revista de Educação Física/ UEM, Maringá, v.12, n.1, p.7-17, 2001.

VISSCHER, C. The role of parental support in sports succes of talented Young dutch athletes. In: COELHO E SILVA, M.; MALINA, R. Children and youth in organized sports. Coimbra: Imprensa da Universidade, 2004.

WEINECK, J. Treinamento ideal. São Paulo: Manole, 1999.

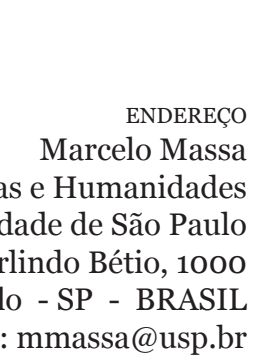

Recebido para publicação: 11/09/2009

1a. Revisão: $18 / 02 / 2010$

2a. Revisão: 31/03/2010

Aceito: 06/05/2010 